\title{
Studies on the isolation and molecular characterization of Lactobacillus spp. from human breast milk and assessment of their probiotic potential
}

\author{
K.B. Chathyushya ${ }^{1}$, Myakala Shiva Prakash ${ }^{2 *}$, Y. Kodandapani ${ }^{3}$, \\ B. Bheema ${ }^{4}$, J.J.G. Babu', Rajkumar Hemalatha ${ }^{5 *}$ \\ ${ }^{1}$ Clinical Epidemiology, ICMR-National Institute of Nutrition, Hyderabad, Telangana, India \\ ${ }^{2}$ Department of Microbiology, ICMR-National Institute of Nutrition, Hyderabad, Telangana, India \\ ${ }^{3}$ Department of Pediatrics, Niloufer Hospital, Osmania Medical College, Hyderabad, Telangana, India \\ ${ }^{4}$ Department of Microbiology, Osmania University, Hyderabad, Telangana, India \\ ${ }^{5}$ ICMR-National Institute of Nutrition, Hyderabad, Telangana, India
}

${ }^{\star}$ Corresponding author, E-mail: drmspnin@gmail.com, rhemalathanin@yahoo.com

\begin{abstract}
Human breast milk is a prominent source for microbiota development in the infant gastrointestinal tract. It is reported that probiotics in breast milk have a major role in the protection of the newborns and as well as infants when compared to formula milk/cow milk fed babies. The aim of the present study was to isolate and identify the probiotics from human breast milk. Fifty healthy women during the first week of postpartum were selected randomly and milk samples were collected aseptically. The samples were screened for probiotic microflora using microbiological methods, including serial dilution and plating on de Man-Rogosa-Sharpe agar. The isolates suspected to be probiotics were selected for morphological, biochemical and molecular characterization and bioinformatics analysis. They were further evaluated for their probiotic potential. Mixed microflora were found: commensal microorganisms like Streptococcus spp., Staphylococcus spp. and Lactobacillus spp. Twelve Lactobacillus spp. were isolated from breast milk, which were confirmed for genus and species by molecular methods and bioinformatics. These Lactobacilli were found to be acid resistant, tolerant to $0.3 \%$ bile and had ability to inhibit the growth of food-borne pathogens. A diversified bacterial population was present in human breast milk, and it was also found to be a rich source for beneficial probiotics, particularly Lactobacillus spp.
\end{abstract}

Key words: human milk, lactic acid bacteria, Lactobacillus, milk microbiome, probiotics.

Abbreviations: ABR, antibiotic resistance; ABS, antibiotic sensitivity; BLAST, basic local alignment search tool; CFU, colony-forming units; HBM, human breast milk; MRS, de Man-Rogosa-Sharpe; MR-VP, methyl red/Voges Proskauer; SDS, sodium dodecyl sulphate.

\section{Introduction}

Human breast milk (HBM) renders a complete nutrition for the newborn. It contains numerous immune substances includes antibodies, cytokines and chemokines, growth factors, immunoglobulins, and hormones (Walker 2010). HBM consists of high amounts of nutrients that are imperative for the growth of infants. These substances plays a crucial role in supporting the development and survival of the infants because of nutrient supply and also due to the transfer of beneficial microbes present in the breast milk (Martin et al. 2016). It is also considered as a postnatal microbial link due to its diversified microflora, which enhances the microbial colonization in the gut of infants (Jost et al. 2014). A breastfed baby consumes approximately $800 \mathrm{~mL}$ milk per day, which amounts to about $1 \times 10^{7}$ bacteria daily (Heikkila, Saris 2003). The microflora present in breast milk represents the very first microbes that enter into human body and plays a crucial role in the infant's development and physiology (CabreraRubio et al. 2012). Establishment of gut microbiota in the infant is a stepwise process, which promotes the immune system by the gut development (Mackie et al. 1999). It has been suggested that an infant's exposure to such a wealth of microbial phyla through breast-feeding may exert a number of useful effects against various diseases (Hunt et al. 2011).

Many studies have proved that breast milk plays an important role in the establishment of the early gut microbiome in infants, where the same microbial flora in the breast milk of the mother was observed in the corresponding infant faeces (Lee et al. 2015; Ho et al. 2018; Madan et al. 2019). Subsequently, many other studies proved that the breast milk microflora was similar with 
the mother's gut microbiome, providing evidence for the entero-mammary pathway (Padilha et al. 2019; Kordy et al. 2020). These bacteria may also play prominent roles in reducing the occurrence and intensity of infections in the breast-fed baby. In fact, some of the beneficial microbiota isolated from breast milk have inhibitory ability against various pathogenic bacteria by competing for adhesion and/or through producing various antibacterial substances like hydrogen peroxide, bacteriocin and organic acids (Beasley, Saris 2004; Olivares et al. 2006; Martin et al. 2015).

Breast milk promotes the establishment, colonization, growth and maturation of the gut microbiome in the infant. Numerous genera and species of bacteria are present in human breast milk, among which bacteria like Lactococcus (Beasley, Saris 2004), Enterococcus (Huang et al. 2019), Pediococcus (Osmanagaoglu et al. 2010), Lactobacillus (Jamyuang et al. 2019) and Bifidobacterium spp. (Martin et al. 2009) are considered as probiotic microorganisms that confer health benefits to the infant. The supply of these beneficial microbes to the newborn gut is through breast feeding, indicating mother-infant microbial exchange through a postnatal route (Solis et al. 2010). The probiotic bacteria originated from milk were found to have good colonization in the human/animal gastrointestinal tract (Monteagudo-Mera et al. 2012). Probiotics isolated from breast milk used to complement food products would have important criteria like having human origin, ability to adapt to dairy substrates, and being safe for consumption by infants (Klaenhammer, Kullen1999; Martin et al. 2004). Although there have been a number studies in this field, probiotic isolates from a certain geographical region and environment would be more adaptable and potentially confer more benefits. The aim of the current study was isolate and characterize probiotic lactic acid bacteria from human breast milk.

\section{Materials and methods}

\section{Collection of material}

Ethical committee approval from the Osmania Medical College hospital (Protocol No: OMC:21/01/2017) and the ICMR-National Institute of Nutrition (NIN Protocol No: 06/11/2016) was obtained before commencement of the study. Recruited mothers received detailed written information of the study and signed consent was obtained from the participants.

A total of about fifty healthy lactating mothers without any metabolic diseases and pre or postnatal complications, were randomly selected from postnatal ward of Niloufer Hospital, Hyderabad. Breast milk samples were collected aseptically from the above subjects within a week after delivery. The mammary areola was cleaned using chlorohexidine to avoid cross contamination of skin flora (Sakwinska et al. 2016). The first few drops were discarded and about $2 \mathrm{~mL}$ of breast milk was collected in a sterile container by manual expression and kept at $4{ }^{\circ} \mathrm{C}$ for laboratory analysis.

\section{Isolation, identification and characterization of probiotic bacteria}

About $1 \mathrm{ml}$ of each breast milk sample was serially diluted in sterile phosphate buffer saline and $100 \mu \mathrm{L}$ of the diluted sample was plated on to de Man-Rogosa-Sharpe agar (Himedia, India). These plates were incubated anaerobically at $37^{\circ} \mathrm{C}$ for 24 to $48 \mathrm{~h}$. After incubation of the culture plates, various colonies suspected for probiotics were selected for identification by morphological, biochemical and molecular characteristics and finally confirmed to species by bioinformatics analysis.

The morphology of the colonies of probiotic microflora was described by size, shape, margin, colour and texture on the agar plate, followed by Gram's staining. The bacterial colonies that were positive in morphological identification were further tested for their biochemical characteristics (indole, methyl red, Voges Prausker and citrate utilization test) along with oxidase and catalase tests (Ahirwar et al. 2017; Ranjan et al. 2020).

For indole test, about $0.1 \mathrm{~mL}$ of overnight grown culture was added to tryptophan broth and incubated at $37^{\circ} \mathrm{C}$ for $24 \mathrm{~h}$, after which $0.5 \mathrm{~mL}$ of Kovac's reagent was added. Appearance of a pink colour ring at the top of the broth layer was considered as a positive result.

The methyl red/Voges Proskauer test was performed after incubating $100 \mu \mathrm{l}$ of overnight grown culture in $10 \mathrm{~mL}$ of the respective medium for $24 \mathrm{~h}$ at $37^{\circ} \mathrm{C}$. The incubated broth was separated in two tubes. Five drops of methyl red indicator was added to one tube and two drops of Barrit's reagent A and three drops of Barrit's reagent B was added into another tube. The change of broth colour to red indicates positive for methyl red and pink colour after adding the Barrit's reagent indicates positive for Voges Proskauer test.

Simmons citrate agar slants were prepared for performing the citrate utilization test. A loopful of overnight grown culture was inoculated on the agar slant and incubated at $37^{\circ} \mathrm{C}$ for $24 \mathrm{~h}$. Appearance of a blue colour at the inoculated site was considered as a positive result.

The oxidase test was performed using oxidase discs supplied by Himedia Laboratories. An isolated colony was picked up with an inoculation needle and spreaded on the oxidase disc in a sterile environment. Appearance of a purplish blue colour within five seconds indicated a positive reaction.

For the catalase test, an isolated colony was picked up and placed on a glass slide. A drop of 3\% hydrogen peroxide was added to the colony and immediate bubble formation indicated a positive reaction for catalase.

Carbohydrate utilization or sugar fermentation test was performed using phenol red as a basal medium (Kavitha et al. 2016). Phenol red broth (5 mL) was added into a tube 
containing individual carbohydrate discs procured from Himedia laboratories. An overnight grown culture of 100 $\mu \mathrm{L}$ was inoculated into the above medium and incubated at $37^{\circ} \mathrm{C}$ for $24 \mathrm{~h}$. The results observed were noted and the samples were further incubated for another $24 \mathrm{~h}$.

\section{Molecular characterization}

The genomic DNA was isolated from overnight bacterial culture according to the modified protocol of Wright et al. (2017). A brief description of the method follows. About $2 \mathrm{~mL}$ of bacterial culture was harvested by centrifugation and the pellet was dissolved in lysozyme $(500 \mu \mathrm{L})$, and then incubated at $37^{\circ} \mathrm{C}$ for $45 \mathrm{~min}$. About $100 \mu \mathrm{L}$ of SDS $(10$ \%), $200 \mu \mathrm{L}$ of $\mathrm{NaCl}$ was then added and the mixture was incubated for an hour. The DNA was extracted from the bacterial cell lysate by adding phenol-chloroform. Further, the isolated DNA was precipitated with $70 \%$ ethanol and dissolved in $50 \mu \mathrm{L}$ TE buffer. The integrity, purity, and concentration of the DNA was confirmed using agarose gel electrophoresis and by checking the OD at $260 / 280 \mathrm{~nm}$ in the nanodrop.

The genus level identification was conducted using PCR with genus-specific primers. The primer sequence required for PCR amplification was adopted from Rekha et al. (2006). A total volume of $20 \mu \mathrm{l}$ reaction contains $10 \mu \mathrm{L}$ of Norgen $2 \mathrm{X}$ Master mix and $1 \mu \mathrm{L}$ of $10 \mu \mathrm{M}$ each primer and template DNA ( $25 \mathrm{ng}$ ) and $7 \mu \mathrm{L}$ of nuclease free water. The amplification conditions for the PCR comprised of a cycle of initial denaturation at $94^{\circ} \mathrm{C}$ for 5 min following denaturation at $94{ }^{\circ} \mathrm{C}$, annealing at $52{ }^{\circ} \mathrm{C}$, extension at 72 ${ }^{\circ} \mathrm{C}$ each for $1 \mathrm{~min}$ for 30 cycles and one cycle of the final extension at $72{ }^{\circ} \mathrm{C}$ for $8 \mathrm{~min}$. After the amplification the amplicons were subjected to gel electrophoresis and observed under UV light in gel doc.

After genus level identification, the PCR products were further proceeded to Sanger sequencing for the 16s rRNA gene (Eurofins Genomics). Primers used for molecular identification were TGCCTAATACATGCAAGTCGA (Lactobacillusforward) andGTTTGGGCCGTGTCTCAGT (Lactobacillus reverse). The forward and reverse sequences generated using Sanger sequencing were assembled to generate the consensus sequence using bioinformatics software Seqman Ultra of DNA star Laser-gene. The obtained consensus sequence was used for identification of species by the Basic local alignment search tool (BLAST) in the genomic database NCBI-Genbank. Further, multiple sequence alignment was performed by Clustal $\mathrm{W}$. Subsequently, the cladogram or the neighbour joining phylogenetic tree was drawn using molecular evolutionary genetic analysis (MEGA-X) software (Saitou, Nei 1987; Tamura et al. 2004; Kumar et al. 2018; Stecher et al. 2020).

\section{Analysis of probiotic properties}

After identification up to the strain level, the isolates were subjected to various probiotic properties. Since the human stomach $\mathrm{pH}$ is 2 , the probiotics were tested for acid resistance at $\mathrm{pH} 2,3$ and 4 in comparison to $\mathrm{pH} 6$, and the same strains were assessed for bile salt tolerance $(0.3 \%)$ (Hassanzadazar et al. 2012).

For the acid resistance test, about $100 \mu \mathrm{L}$ of overnight culture was inoculated into MRS broth previously adjusted to $\mathrm{pH} 2,3$ and 4 using $1 \mathrm{~N} \mathrm{HCl}$ and incubated at $37^{\circ} \mathrm{C}$ for 3 h. MRS broth without adjusting the $\mathrm{pH}$ served as a control. The viable bacteria was counted by taking $100 \mu \mathrm{L}$ of each sample every hour for $3 \mathrm{~h}$ using the spread plate method and these experiments were done in duplicate.

For the bile tolerance test, about $100 \mu \mathrm{L}$ of overnight culture was inoculated into MRS broth with $0.3 \%$ ox-bile (Himedia) and incubated at $37^{\circ} \mathrm{C}$ for $3 \mathrm{~h}$. Normal MRS broth without adding bile served as a control. The viable bacteria was counted by taking $100 \mu \mathrm{L}$ of each sample every hour for $3 \mathrm{~h}$ using the spread plate method and these experiments were done in duplicate.

The antibiotic susceptibility of the isolated strains was assessed by the disc diffusion method using common antibiotics for paediatrics and discs supplied by Himedia laboratories. About $100 \mu \mathrm{L}$ of freshly grown Lactobacillus culture was spread on MRS agar plates. Then, the antibiotic discs were placed on the agar plates and incubated at 37 ${ }^{\circ} \mathrm{C}$ for 24 to $48 \mathrm{~h}$. The zone of inhibition by the isolates was noted accordingly. An antibiotic susceptibility pattern was obtained using amikacin $(30 \mu \mathrm{g})$, amoxycillin $(30 \mu \mathrm{g})$, cephotaxime $(30 \mu \mathrm{g})$, ciprofloxacin $(30 \mu \mathrm{g})$, cotrimoxazole $(25 \mu \mathrm{g})$, methicillin $(5 \mu \mathrm{g})$, metronidazole $(5 \mu \mathrm{g})$ and norfloxacin $(10 \mu \mathrm{g})$.

\section{Analysis of antagonistic properties}

Pathogenic bacterial cultures that are responsible for food-borne illness were procured from National culture collection centres, NCCS, Pune and MTCC, Chandigarh India. The lyophilized cultures were revived by adding into nutrient broth and re-culturing twice before performing the experiment. The indicator organisms used for the assay were Escherichia coli (MCC 2412), Pseudomonas aeruginosa (MCC 2080), Staphylococcus aureus (MCC 2408), Salmonella typhi (MTCC 3224) and Bacillus cereus (NCDC 240)

The antimicrobial activity of the isolates was studied using the agar well diffusion method. The indicator organisms were inoculated and incubated in nutrient broth at $37^{\circ} \mathrm{C}$ for 16 to $18 \mathrm{~h}$. These overnight cultures were plated on the agar plates. The wells were punctured using a sterile cork borer and about $50 \mu \mathrm{L}$ of the culture broth with isolates was loaded into the well (Karimi et al. 2018).

\section{Statistical analysis}

IBM-SPSS software was used to perform the statistical analysis: univariate post hoc multiple comparison using Dunnet's test at $5 \%$ level of significance. Bar charts were plotted for quantitative data like acid resistance and bile tolerance using Microsoft Excel 2019. The data was presented in the form log CFU per $\mathrm{mL}$. 
Table 1. Cafrbohydrate utilization test for the isolates. -, no colour change; + orange colour; ++, yellow colour

\begin{tabular}{|c|c|c|c|c|c|c|c|c|c|c|c|c|}
\hline Carbohydrate & 1 & 2 & 3 & 4 & 5 & 6 & 7 & 8 & 9 & 10 & 11 & 12 \\
\hline Sucrose & ++ & ++ & ++ & ++ & ++ & ++ & ++ & ++ & ++ & ++ & ++ & ++ \\
\hline Galactose & ++ & ++ & ++ & ++ & ++ & ++ & ++ & ++ & ++ & ++ & ++ & ++ \\
\hline Mannitol & ++ & ++ & ++ & ++ & ++ & - & ++ & ++ & ++ & ++ & ++ & ++ \\
\hline Inulin & - & - & - & - & - & - & - & - & - & - & - & - \\
\hline Cellobiose & ++ & ++ & ++ & ++ & ++ & ++ & ++ & ++ & ++ & ++ & ++ & ++ \\
\hline Dulcitol & - & - & - & - & - & - & - & - & - & - & - & - \\
\hline Rhamnose & - & - & - & - & - & - & - & - & - & - & - & - \\
\hline Adonitol & - & - & - & - & - & - & - & - & - & - & - & - \\
\hline Raffinose & - & - & - & - & - & - & - & - & - & - & - & - \\
\hline Salicin & ++ & ++ & ++ & ++ & ++ & ++ & ++ & ++ & ++ & ++ & ++ & ++ \\
\hline Mannose & ++ & ++ & ++ & ++ & ++ & ++ & ++ & ++ & ++ & ++ & ++ & ++ \\
\hline Inositol & - & - & - & - & - & - & - & - & - & - & - & - \\
\hline Xylose & - & - & - & - & - & - & - & - & - & - & - & - \\
\hline Dextrose & ++ & ++ & ++ & ++ & ++ & ++ & ++ & ++ & ++ & ++ & ++ & ++ \\
\hline Trehalose & ++ & ++ & ++ & ++ & ++ & ++ & ++ & ++ & ++ & ++ & ++ & ++ \\
\hline Melibiose & ++ & ++ & - & ++ & ++ & ++ & ++ & ++ & ++ & ++ & ++ & ++ \\
\hline Sorbitol & - & - & - & - & - & - & - & - & - & - & - & - \\
\hline Fructose & ++ & ++ & ++ & ++ & ++ & ++ & ++ & ++ & ++ & ++ & ++ & ++ \\
\hline Arabinose & + & + & + & + & + & + & + & + & + & + & + & + \\
\hline
\end{tabular}

\section{Results}

\section{Identification of isolates}

Among the fifty breast milk samples collected, diversified commensal microorganisms like Streptococcus, Staphylococcus, Diplococcus and Bacillus etc. were found. Microbial colonies that were small, circular, creamishwhite, pin point with entire margin and were Gram positive rod shaped bacteria were considered for further identification.

Further, all of the isolated probiotics were found to be non-reactive for the biochemical tests performed i.e. no bubble formation for catalase, no change in colour on an oxidase disc, an indole ring was not observed after addition of Kovac's reagent, MR-VP medium did not turn red after adding methyl red indicator, no colour change was found after addition of Barrit's reagent for the Voges-Proskauer test and no change in colour was observed for the citrate utilization test.

A change in colour of phenol red broth from fuchsin red to orange showed week positive and red to yellow was considered to be strongly positive. The utilization of carbohydrates by the probiotics is shown in Table 1 .

About 12 isolates from different human breast milk samples were identified as the genus Lactobacillus by observing the amplified DNA product at $318 \mathrm{bp}$. After performing the BLAST search of the sequences assembled from 16s rDNA sequencing, the top hit strains with lowest

Table 2. Identification of isolates after blast in NCBI Genebank

\begin{tabular}{|c|c|c|c|c|}
\hline No. & Sample & Bacteria & Similarity & Source and reference \\
\hline 1 & HBM-1 & $\begin{array}{l}\text { Lactobacillus delbrueckii subsp. lactis } \\
\text { AB289+092.1 }\end{array}$ & $82.35 \%$ & Native milk (Germond et al. 2021) \\
\hline 2 & HBM-2 & Lacticaseibacillus casei MT045986.1 & $82.40 \%$ & Breast milk and infant gut (Martin et al. 2007) \\
\hline 3 & HBM-3 & Lactobacillus crispatus AB911456.1 & $77.89 \%$ & $\begin{array}{l}\text { Women of reproductive age (van der Veer et al. } \\
\text { 2019; Zhang 2020) }\end{array}$ \\
\hline 4 & HBM-4 & Lactobacillus acidophilus MN173898.1 & $80.61 \%$ & Breast milk (Mehanna 2013) \\
\hline 5 & HBM-5 & Lacticaseibacillus casei MT045967.1 & $80.66 \%$ & Breast milk and infant gut (Martin et al. 2007) \\
\hline 6 & HBM-6 & Uncultured Lactobacillus LT677946.1 & $80.22 \%$ & - \\
\hline 7 & HBM-7 & Lactobacillus acidophilus MW063498.1 & $78.63 \%$ & Breast milk (Mehanna 2013) \\
\hline 8 & HBM-8 & Lactobacillus helveticus KX247766.1 & $91.14 \%$ & Breast milk (Zhang 2020) \\
\hline 9 & HBM-9 & Lactobacillus helveticus KX247766.1 & $89.84 \%$ & Breast milk (Zhang 2020) \\
\hline 10 & HBM-10 & Lactobacillus delbrueckii MH392983.1 & $95.74 \%$ & Breast milk (Zhang 2020) \\
\hline 11 & HBM-11 & Lactobacillus acidophilus MW063498.1 & $90.67 \%$ & Breast milk (Mehanna 2013) \\
\hline 12 & HBM-12 & Lactobacillus acidophilus HE793099.1 & $99.68 \%$ & Breast milk (Mehanna 2013) \\
\hline
\end{tabular}




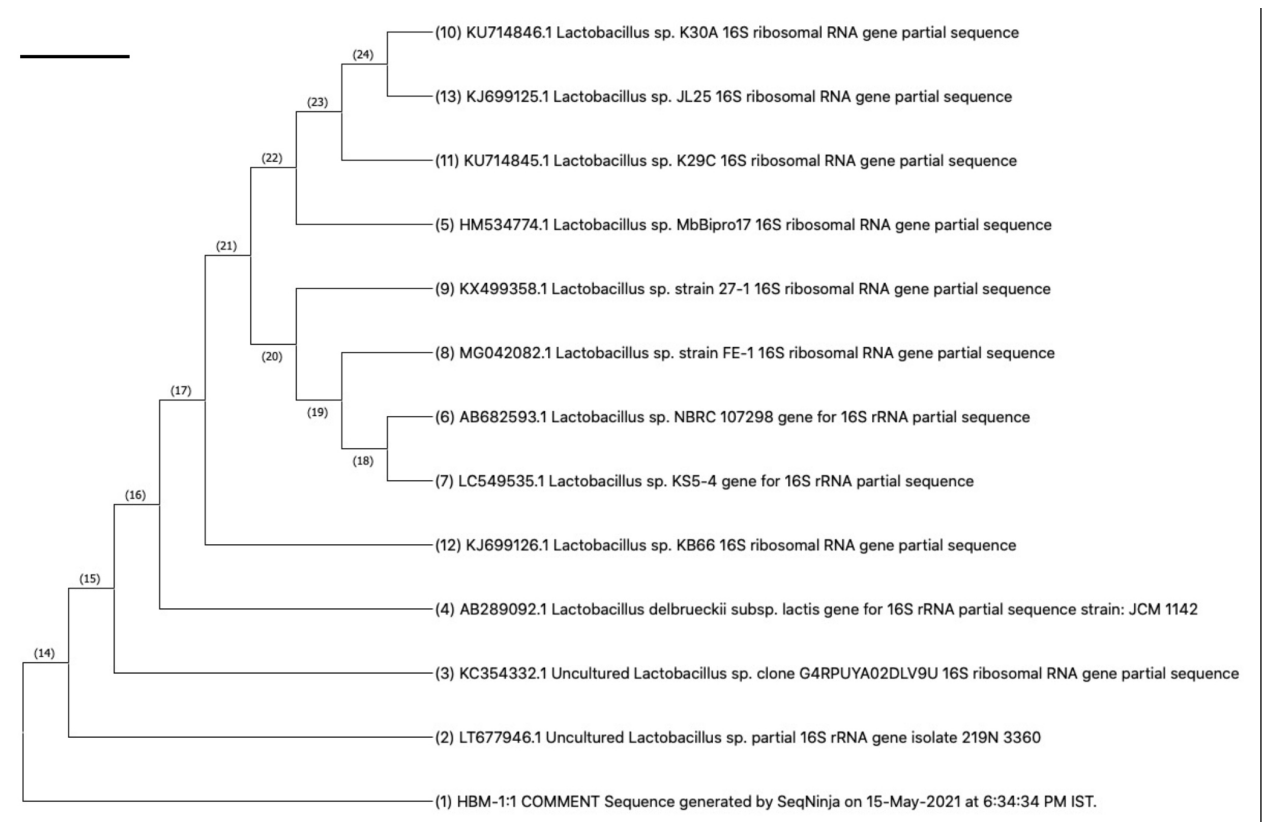

Fig. 1. Phylogenetic tree of isolate HBM-1 constructed using Mega X software

e-value and highest query coverage and similarity were considered as the best matches (Table 2 and Fig. 1). All of these isolates were identified to be species of the genus Lactobacillus.

\section{Characterization of isolates}

Isolates were cultivated at different low $\mathrm{pH}$ values to estimate their tolerance to acidity (Figs. 2 to 5). All of the strains of Lactobacilli were found to be resistant to acidic $\mathrm{pH}$ values 2, 3 and 4, excluding five isolates (Nos. $1,4,7,10$ and 12), as these isolates were able to survive till $\mathrm{pH}$ 3. However, the viability of these Lactobacilli isolates decreased significantly upon incubation at $\mathrm{pH} 2$ for $3 \mathrm{~h}$. Comparison between the isolates in cell viability after 1 and $3 \mathrm{~h}$ of incubation indicated similar $\mathrm{pH}$ resistance.
The isolates of Lactobacilli from human breast milk were found to be tolerant to $0.3 \%$ bile, excluding isolate No. 9 (Fig. 6). However, this isolate was found to be tolerant to this bile concentration up to an hour after incubation at 37 ${ }^{\circ} \mathrm{C}$. The viability of all these microflora seems to increase significantly after incubation at $37^{\circ} \mathrm{C}$ for $3 \mathrm{~h}$. The viability of the strains was similar, excluding isolate No. 9 , as this isolate was able to survive up to one hour at $0.3 \%$ bile.

The results obtained for antibiotic sensitivity/resistance show that all of the probiotics were resistant to methicillin and metronidazole at $5 \mu \mathrm{g}$ concentration (Table 3). Two of the Lactobacilli - No. 4 and No. 5 - were found to be resistant to several antibiotics, but few probiotics showed resistance to other antibiotics.

All of the Lactobacillus had inhibitory effect on

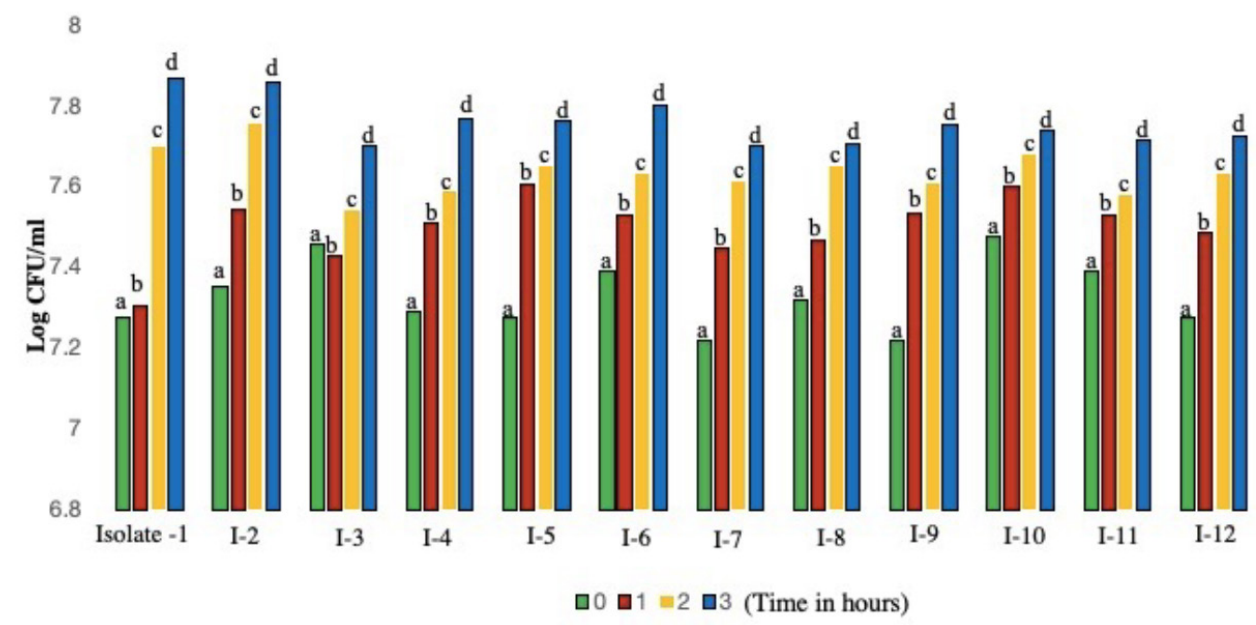

Fig. 2. Growth of the isolates at pH 6. Multiple means were compared using Dunnet test. Different letters indicate statistically significant $(p<0.05)$ differences from control (time $0 \mathrm{~h})$. 


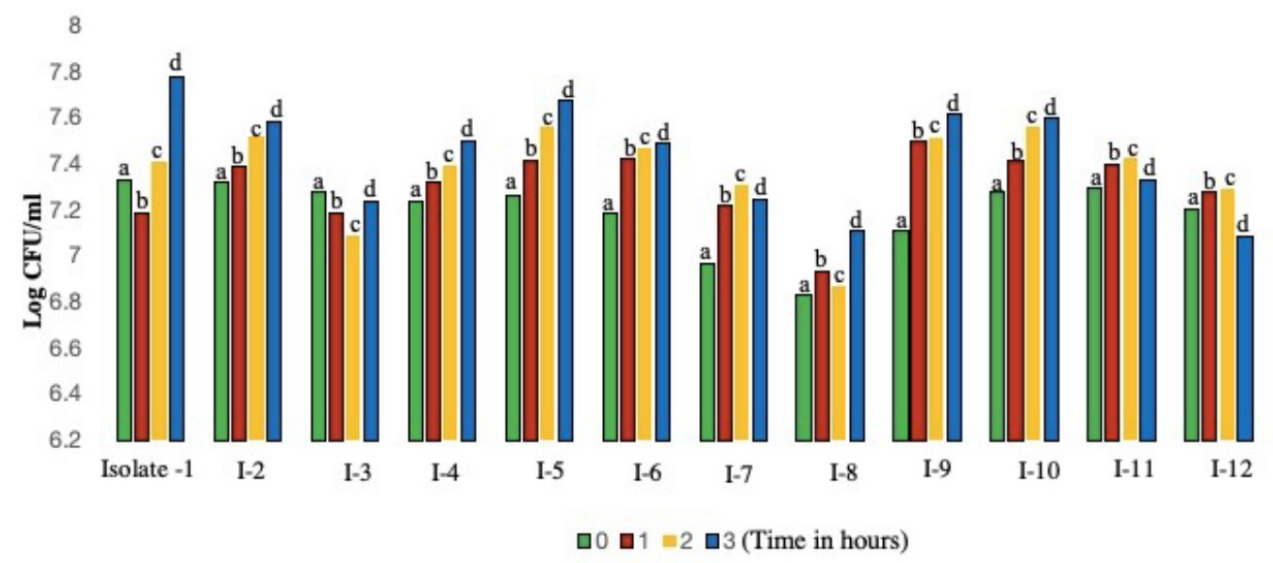

Fig. 3. Growth of the isolates at $\mathrm{pH}$ 4. Multiple means were compared using Dunnet test. Different letters indicate statistically significant $(p<0.05)$ differences from control (time $0 \mathrm{~h})$.

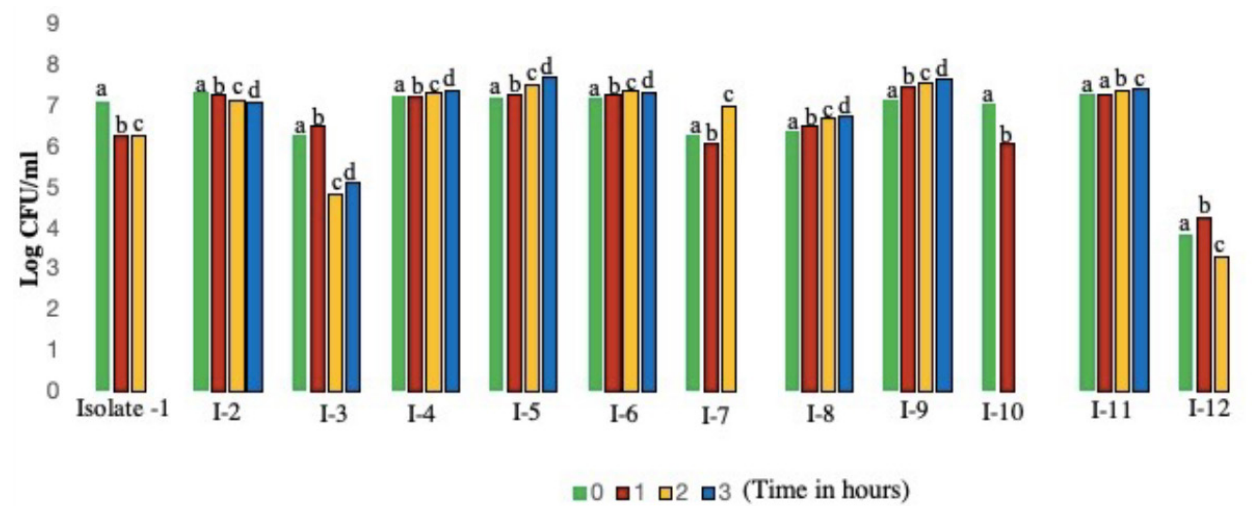

Fig. 4. Growth of the isolates at $\mathrm{pH}$ 3. Multiple means were compared using Dunnet test. Different letters indicate statistically significant $(p<0.05)$ differences from control (time $0 \mathrm{~h})$.

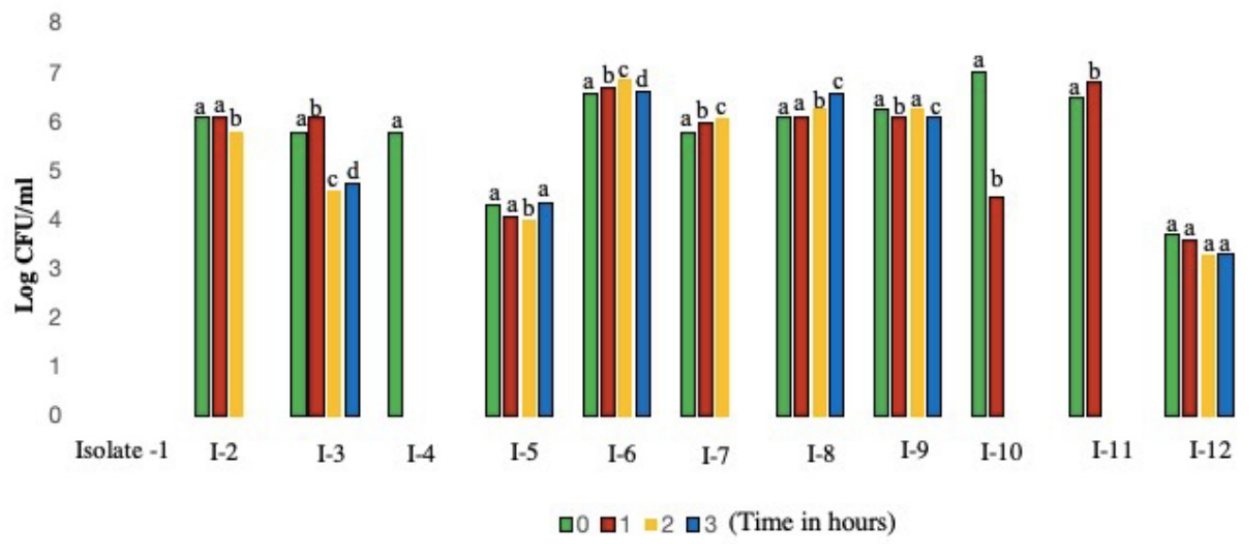

Fig. 5. Growth of the isolates at $\mathrm{pH}$ 2. Multiple means were compared using Dunnet test. Different letters indicate statistically significant $(p<0.05)$ differences from control (time $0 \mathrm{~h})$.

Pseudomonas aeroginosa (Table 4). The other isolates (No. 1,2,9 and 12) had inhibitory effect on all of the pathogenic organisms used in this experiment. However, most isolated probiotics did not show antagonistic properties against Escherichia coli.

\section{Discussion}

In the present study, we isolated lactic acid bacteria i.e., Lactobacillus spp. from human breast milk of lactating women during the first week of postpartum. The Lactobacilli 


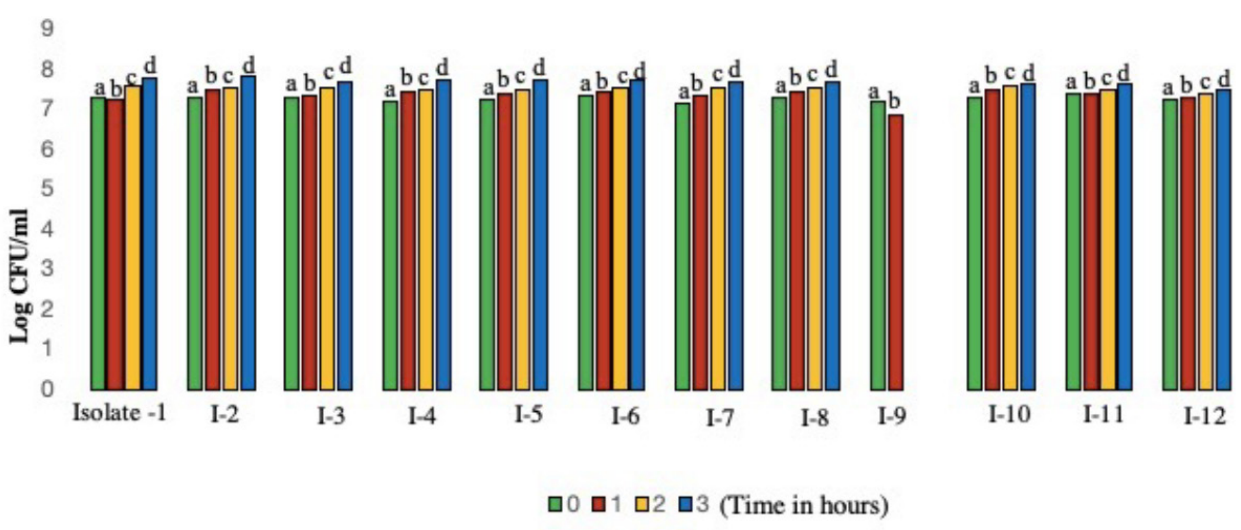

Fig. 6. Growth of the isolates at $0.3 \%$ bile. Multiple means were compared using Dunnet test. Different letters indicate statistically significant $(p<0.05)$ differences from control (time $0 \mathrm{~h})$.

species identified in the breast milk of the mothers participating in this study were the same as reported in other studies (Heikkila, Saris 2003; Martin et al. 2003). The occurrence of these probiotics in breast milk is associated with that of prebiotic substances present in this same fluid (Kralj et al. 2002; van Hijum et al. 2002).

Lactobacilli strains in human milk contribute to digestion by the breakdown of complex sugars and proteins in the infant gut, resulting in an increase in the production of certain functional metabolites, such as butyrate, which modulates the function of intestine (Maldonado et al. 2010; Gil-Campos et al. 2012). It was also demonstrated in some studies that the rate of infectious diseases is lower in breastfed infants when compared to infants fed with supplemented milk products, proving the anti-infective properties of breast milk. The isolation of these probiotic lactic acid bacteria from human breast milk could be beneficial to the development of intestinal microbiota and immunity of infants that cannot be breast fed due to various reasons (Ajetunmobi et al. 2015). Considering their ability to adapt and colonize in the human intestine, the isolated Lactobacilli from breast milk are excellent candidates for developing probiotic based products (Martin et al. 2006).

All of the species identified in the bioinformatics analysis in this study were found to be similar to those reported in a number of other studies conducted on human breast milk (Germond et al. 2003; Mehanna et al. 2013; Van der Veer et al. 2019; Zhang et al. 2020). This indicates that probiotics, particularly Lactobacillus spp., are universally present in human breast milk. Based on the available information, breast milk is a potential source for probiotic lactic acid bacteria. Hence, it can be considered to be a natural symbiont-containing food harbouring a combination of probiotics and prebiotics that may ultimately foster specific health-benefiting microbiota in the infant gut (Asakuma et al. 2011; Zivkovic et al. 2011). The results of biochemical

Table 3. Antibiotic susceptibility of the isolates. +, zone of inhibition $\leq 4 \mathrm{~mm}$; ++, zone of inhibition $\geq 5 \mathrm{~mm}$; - no zone of inhibition

\begin{tabular}{|c|c|c|c|c|c|c|c|c|c|c|c|c|}
\hline Antibiotic & 1 & 2 & 3 & 4 & 5 & 6 & 7 & 8 & 9 & 10 & 11 & 12 \\
\hline Amikacin $30 \mu \mathrm{g}$ & ++ & ++ & ++ & ++ & ++ & ++ & ++ & ++ & ++ & + & ++ & + \\
\hline Amoxycillin $30 \mu \mathrm{g}$ & ++ & + & + & + & - & ++ & + & + & ++ & + & + & + \\
\hline Cephotaxime $30 \mu \mathrm{g}$ & ++ & - & - & - & - & - & - & + & + & - & - & - \\
\hline Ciprofloxacin $30 \mu \mathrm{g}$ & ++ & ++ & ++ & ++ & ++ & ++ & ++ & ++ & ++ & ++ & ++ & ++ \\
\hline Cotrimoxazole $25 \mu \mathrm{g}$ & ++ & + & ++ & - & - & ++ & - & - & ++ & - & + & ++ \\
\hline Methicillin $5 \mu \mathrm{g}$ & - & - & - & - & - & - & - & - & - & - & - & - \\
\hline Metronidazole $5 \mu \mathrm{g}$ & - & - & - & - & - & - & - & - & - & - & - & - \\
\hline Norfloxacin $10 \mu \mathrm{g}$ & ++ & ++ & ++ & - & + & ++ & + & ++ & ++ & + & ++ & ++ \\
\hline
\end{tabular}

Table 4. Antagonistic property of the isolates against various food borne pathogens. + , zone of inhibition $\leq 4 \mathrm{~mm}$; ++, zone of inhibition $\geq 5 \mathrm{~mm}$; - no zone of inhibition

\begin{tabular}{|c|c|c|c|c|c|c|c|c|c|c|c|c|}
\hline Pathogen & 1 & 2 & 3 & 4 & 5 & 6 & 7 & 8 & 9 & 10 & 11 & 12 \\
\hline Escherichia coli & + & + & - & - & - & - & - & - & + & - & - & + \\
\hline Pseudomonas aeroginosa & + & + & + & + & + & ++ & + & + & ++ & + & + & ++ \\
\hline Staphylococcus aureus & + & + & - & + & + & + & + & + & ++ & - & + & ++ \\
\hline Staphylococcus typhi & ++ & + & + & + & + & + & + & + & + & - & - & ++ \\
\hline Bacillus cereus & + & + & - & - & + & + & + & + & + & ++ & + & + \\
\hline
\end{tabular}


and carbohydrate tests were found to be similar to results of other studies performed on Lactobacillus isolates (Kavitha et al. 2016; Mannan et al. 2017).

Certain acids like hydrochloric acid found in the human stomach, disrupt biomolecules such as proteins, fatty acids and nucleic acids of cells (Chan et al. 2011). Other studies found that exposure of probiotic bacteria to gastric acid for $3 \mathrm{~h}$ incubation reduced the viability count intensively (Mandal et al. 2006). The results of our study are in agreement with the above studies, as the viability of the isolated bacteria decreased with increase in acidity. However, although the viability decreased, they were able to survive at $\mathrm{pH} 2$. The probiotics were also able to tolerate an intestinal bile concentration of $0.3 \%$, showing their ability to survive in the intestinal environment.

In evaluating the safety aspects of probiotics for use in human health, antibiotic susceptibility testing plays an important role, as these do not possess transferable genes that are antibiotic resistant (Anandharaj et al. 2015). However, the risk of gene transfer is considerably low for intrinsic resistance because these mutations are found in chromosomes (Gueimonde et al. 2013). Although the resistance of probiotic lactic acid bacteria strains to antibiotics is an important concern for probiotic applications, there might be certain errors in the testing methods used for determining antibiotic resistance (Huys et al. 2002). In our study, the isolated probiotics showed resistance to a few commonly used antibiotics. This resistance might be because of the frequent intake of antibiotics by the mothers before conception, as these organisms are native in the human gut. As previously shown, the frequent intake of antibiotics triggers the $\beta$-lactamase present in the bacteria, which causes antibiotic resistance towards various antibiotics. Similar results were also observed by Coppola et al. 2005 and Hleba et al. 2011, where they have identified antibiotic resistance of bacteria isolated from various sources and found that this resistance varied. Nevertheless, as the probiotics are labelled generally recognised as safe organisms, they should not possess transferable antibiotic resistance genes. However, the safety parameters are also need to be studied before considering the probiotics for use in development of probiotic products.

Further, we also examined the antagonistic activity of the identified Lactobacillus spp., which had human origin. The probiotic Lactobacillus spp. were found to have inhibitory effect towards certain food-borne pathogens. This property was due to the antimicrobial substances released by the probiotic microorganisms as a part of their cell cycle. These substances include organic acids such as formic acid, benzoic acid, acetic acid, phenyl-lactic acid, short chain fatty acid, and other substances like acetaldehyde, acetoin, carbon dioxide, diacetyl, hydrogen peroxide along with bacteriocins (Ammor et al. 2006; Tharmaraj, Shah 2009; Choi, Chang 2015). The type of bacteriocin differs according to the species of bacteria and these include enterocin, enterolysin, lacticin, lactocin, nisin, pediocin, pisciolin, plantaricin and reuterin (Suskovic et al. 2010; Arques et al. 2015).

\section{Conclusions}

The results obtained in this study showed that human breast milk is a potential source of probiotic microflora. Since these probiotics are of human origin and can be treated as indigenous, they can easily adapt to human gut environment and colonize in the human intestine. Hence, the Lactobacillus strains isolated from human breast milk are found to have promising probiotic potential and can be conveniently incorporated in the development of probiotic based food supplements for human health.

\section{Acknowledgements}

The authors acknowledge Department of Biotechnology for providing a Junior Research Fellowship (JRF / SRF) to Ms. Chathyushya K.B. for pursuing her PhD. Further we wish to thank The Director, National Institute of Nutrition (ICMR-NIN) for providing financial assistance for the research project. The authors declare no conflicts of interest. This paper was originally presented in ASM-Microbe-2018, organized by the American Society of Microbiology at GA, USA.

\section{References}

Ahirwar S.S., Gupta M.K., Gupta G., Singh V. 2017. Screening, isolation and identification of lactobacillus species from dental caries of children. Int. J. Curr. Microbiol. Appl. Sci. 6: 497-503.

Ajetunmobi O.M., Whyte B., Chalmers J., Tappin D.M., Wolfson L., Fleming M., MacDonald A., Wood R., Stockton D. L. 2015. Breastfeeding is associated with reduced childhood hospitalization: evidence from a Scottish Birth Cohort 19972009. J. Pediatr. 166: 620-654.

Ammor S., Tauveron G., Dufour E., Chevallier I. 2006. Antibacterial activity of lactic acid bacteria against spoilage and pathogenic bacteria isolated from the same meat smallscale facility. Food Control 17: 454-461.

Anandharaj M., Sivasankari B., Santhanakaruppu R., Manimaran M., Rani R.P., Sivakumar S. 2015. Determining the probiotic potential of cholesterol-reducing Lactobacillus and Weissella strains isolated from gherkins (fermented cucumber) and south Indian fermented koozh. Res. Microbiol. 166: 428-439.

Arques J.L., Rodriguez E., Langa S., Landele J.M., Medina M. 2015. Antimicrobial activity of lactic acid bacteria in dairy products and gut: effect on pathogens. BioMed Res. Int. 2015: 9.

Asakuma S., Hatakeyama E., Urashima T., Yoshida E., Katayama T., Yamamoto K., Kumagai H., Ashida H., Hirose J., Kitaoka M. 2011. Physiology of consumption of human milk oligosaccharides by infant gut-associated bifidobacterial. J. Biol. Chem. 286: 34583-34592.

Beasley S.S., Saris P.E. 2004. Nisin-producing Lactococcus lactis strains isolated from human milk. Appl. Environ. Microbiol. 70: 5051-5053.

Cabrera-Rubio R., Collado M.C., Laitinen K., Salminen S., Isolauri 
E., Mira A. 2012. The human milk microbiome changes over lactation and is shaped by maternal weight and mode of delivery. Am. J. Clin. Nutr. 96: 544-551.

Choi E.A., Chang H.C. 2015. Cholesterol-lowering effects of a putative probiotic strain Lactobacillus plantarum EM isolated from kimchi. LWT Food Sci. Technol. 62: 210-217.

Coppola R., Succi M., Tremonte P., Reale A., Salzano G., Sorrentino E. 2005. Antibiotic susceptibility of Lactobacillus rhamnosus strains isolated from Parmigiano Reggiano cheese. Le Lait 85:193-204.

Germond J.-E., Lapierre L., Delley M., Mollet B., Felis G.E., Dellaglio F. 2003. Evolution of the bacterial species Lactobacillus delbrueckii: a partial genomic study with reflections on prokaryotic species concept. Mol. Biol. Evol. 20: 93-104.

Gil-Campos M., López M.Á., Rodriguez-Benítez M.V., Romero J., Roncero I., Linares M.D., Maldonado J., López-Huertas E., Berwind R., Ritzenthaler K.L., Navas V., Sierra C., Sempere L., Geerlings A., Maldonado-Lobón J.A., Valero A.D., LaraVilloslada F., Olivares M. 2012. Lactobacillus fermentum CECT 5716 is safe and well tolerated in infants of 1-6 months of age: a randomized controlled trial. Pharmacol. Res. 65: 231-238.

Gueimonde M., Sánchez B., de los Reyes-Gavilán C.G., Margolles A. 2013. Antibiotic resistance in probiotic bacteria. Front. Microbiol. 4: 202.

Hassanzadazar H., Ehsani A., Mardani K., Hesari J. 2012. Investigation of antibacterial, acid and bile tolerance properties of lactobacilli isolated from Koozeh cheese. Veterin. Res. Forum 3: 181-185.

Heikkila M.P., Saris P.E. 2003. Inhibition of Staphylococcus aureus by the commensal bacteria of human milk. J. Appl. Microbiol. 95: 471-478.

Hleba L., Kacaniova M., Lejkova J., Pochop J. 2011. Antibiotic resistance of Enterobacteriaceae species 19. associated with faecal bacterial cenosis of ducks. Animal Sci. Biotechnol. 44: 408-414.

Ho N.T., Li F., Lee-Sarwar K.A., Tun H.M., Brown B.P., Pannaraj P.S., Bender J.M., Azad M.B., Thompson A.L., Weiss S.T., Azcarate-Peril M.A., Litonjua A.A., Kozyrskyj A.L., Jaspan H.B., Aldrovandi G.M., Kuhn L. 2018. Meta-analysis of effects of exclusive breastfeeding on infant gut microbiota across populations. Nature Comm. 9: 4169.

Huang M.S., Cheng C.C., Tseng S.Y., Lin Y.L., Lo H.M., Chen P.W. 2019. Most commensally bacterial strains in human milk of healthy mothers display multiple antibiotic resistance. Microbiol. Open 8: e00618.

Hunt K.M., Foster J.A., Forney L.J., Schütte U.M.E., Beck D.L., Abdo Z., Fox L.K., Williams J.E., McGuire M.K., McGuire M.A.. 2011. Characterization of the diversity and temporal stability of bacterial communities in human milk. PLoS One 6: e21313

Huys G., D'haene K., Swings J. 2002. Influence of the culture medium on antibiotic susceptibility testing of food-associated lactic acid bacteria with the agar overlay disc diffusion method. Lett. Appl. Microbiol. 34: 402-406.

Jamyuang C., Phoonlapdacha P., Chongviriyaphan N., Chanput W., Nitisinprasert S., Nakphaichit M. 2019. Characterization and probiotic properties of Lactobacilli from human breast milk. 3 Biotech 9: 398 .

Jost T., Lacroix C., Braegger C., Rochat F., Chassard C. 2014. Vertical mother-neonate transfer of maternal gut bacteria via breastfeeding. Environ. Microbiol. 16: 2891-2904.

Karimi S., Azizi F., Nayeb-Aghaee M., Mahmoodnia L. 2018. The antimicrobial activity of probiotic bacteria Escherichia coli isolated from different natural sources against hemorrhagic $E$. coli O157:H7. Electr. Physician 10: 6548-6553.

Kavitha P., Sindhuja D., Banumathi M. 2016. Isolation and biochemical characterization of Lactobacillus species isolated from Dahi. Int. J. Curr. Microbiol. Appl. Sci. 5: 1042-1049.

Klaenhammer T.R., Kullen M.J. 1999. Selection and design of probiotics. Int. J. Food Microbiol. 50: 45-57.

Kordy K., Gaufin T., Mwangi M., Li F., Cerini C., Lee D.J., Adisetiyo H., Woodward C., Pannaraj P.S., Tobin N.H., Aldrovandi G.M. 2020. Contributions to human breast milk microbiome and enteromammary transfer of Bifidobacterium breve. PLoS One 15: e0219633.

Kralj S., van Geel-Schutten G.H., Rahaoui H., Leer R.J., Faber E.J., van der Maarel M.J.E.C., Dijkhuizen L.. 2002. Molecular characterization of a novel glucosyltransferase from Lactobacillus reuteri strain 121 synthesizing a unique, highly branched glucan with $\alpha-(1 \rightarrow 4)$ and $\alpha-(1 \rightarrow 6)$ glucosidic bonds. Appl. Environ. Microbiol. 68: 4283-4291.

Kumar S., Stecher G., Li M., Knyaz C., Tamura K. 2018. MEGA $\mathrm{X}$ : Molecular evolutionary genetics analysis across computing platforms. Mol. Biol. Evol. 35: 1547-1549.

Lee S.A., Lim J.Y., Kim B.S., Cho S.J., Kim N.Y., Kim O.B., Kim Y. 2015. Comparison of the gut microbiota profile in breast-fed and formula-fed Korean infants using pyrosequencing. Nutr. Res. Pract. 9: 242-248.

Mackie R.I., Sghir A., Gaskins H.R. 1999. Developmental microbial ecology of the neonatal gastrointestinal tract. Am. J. Clin. Nutr. 69: 1035S-1045S.

Madan J.C., Hoen A.G., Lundgren S.N., Farzan S.F., Cottingham K.L., Morrison H.G., Sogin M.L., Li H., Moore J.H., Karagas M.R. 2016. Association of cesarean delivery and formula supplementation with the intestinal microbiome of 6-weekold infants. JAMA Pediatr. 170: 212-219.

Maldonado J., Lara-Villoslada F., Sierra S., Sempere L., Gómez M., Rodriguez J.M., Boza J., Xaus J., Olivares M. 2010. Safety and tolerance of the human milk probiotic strain Lactobacillus salivarius CECT5713 in 6-month-old children. Nutr. J. 26: 1082-1087.

Mandal S., Puniya A.K., Singh K. 2006. Effect of alginate concentration on survival of encapsulated Lactobacillus casei NCDC-298. Int. Dairy J. 16: 1190-1195.

Mannan S.J., Rezwan R., Rahman M.S., Koinur Begum K. 2017. Isolation and biochemical characterization of Lactobacillus species from yogurt and cheese samples in Dhaka Metropolitan Area. Bangladesh Pharmac. J. 20: 27-33.

Martin C.R., Ling P.R., Blackburn G.L. 2016. Review of infant feeding: key features of breast milk and infant formula. Nutrients 8: 279.

Martin R., Jimenez E., Heilig H., Fernández L., Marín M.L., Zoetendal E.G., Rodríguez J.M. 2009. Isolation of Bifidobacteria from breast milk and assessment of the bifidobacterial population by PCR-denaturing gradient gel electrophoresis and quantitative real-time PCR. Appl. Environ. Microbiol. 75: 965-969.

Martin R., Jimenez E., Olivares M., Marin M.L., Fernandez L., Xaus J., Rodriguez J.M. 2006. Lactobacillus salivarius CECT 5713, a potential probiotic strain isolated from infant feces and breast milk of a mother-child pair. Int. J. Food Microbiol. 112: 35-43. 
Martin R., Langa S., Reviriego C., Jimenez E., Marin L.M., Olivares M., Boza J., Jimenez J., Fernandez L., Xaus J., Rodriguez J.M. 2004. The commensal microflora of human milk: New perspectives for food bacteriotherapy and probiotics. Trends Food Sci. Technol. 15: 121-127.

Martín R., Langa S., Reviriego C., Jimínez E., Marín M.L., Xaus J., Fernández L., Rodríguez J.M. 2003. Human milk is a source of lactic acid bacteria for the infant gut. J. Pediatr. 143: 754-758.

Martín R., Olivares M., Marín M.L., Fernández L., Xaus J., Rodríguez J. M. 2005. Probiotic potential of 3 lactobacilli strains isolated from breast milk. J. Hum. Lact. 21: 8-17.

Mehanna N.S., Tawfik N.F., Salem M.M., Effat B.A., Gad El-Rab D.A. 2013. Assessment of potential probiotic bacteria isolated from breast milk. Middle-East J. Sci. Res. 14: 354-360.

Monteagudo-Mera A., Rodriguez-Aparicio L., Rua J., MartinezBlanco H., Navas N., Garcia-Armesto M.R., Ferrero M.A. 2012. In vitro evaluation of physiological probiotic properties of different lactic acid bacteria strains of dairy and human origin. J. Funct. Foods 4: 531-541.

Olivares M., Díaz-Ropero M.P., Martín R., Rodríguez J.M., Xaus J. 2006. Antimicrobial potential of four Lactobacillus strains isolated from breast milk. J. Appl. Microbiol. 101: 72-79.

Osmanagaoglu O., Kiran F., Ataoglu H. 2010. Evaluation of in vitro probiotic potential of Pediococcus pentosaceus OZF isolated from human breast milk. Probiot. Antimicrob. Prot. 2: $162-174$

Padilha M., Danneskiold-Samsøe N.B., Brejnrod A., Hoffmann C., Cabral V.P., Iaucci J.M., Sales C.H., Fisberg R.M., Cortez R.V., Brix S., Taddei C.R., Kristiansen K., Saad S.M.I. 2019. The human milk microbiota is modulated by maternal diet. Microorganisms 7: 502.

Ranjan K.G., Sankar G.G., Raju S.D.V.V. 2020. Isolation and characterization of commercial probiotics. Int. J. Res. Pharm. Sci. 11: 818-825.

Rekha R., Rizvi M.A., Jaishree P. 2006. Designing and validation of genus-specific primers for human gut flora study. Electr. J. Biotechnol. 9: 2.

Saitou N., Nei M. 1987. The neighbor-joining method: A new method for reconstructing phylogenetic trees. Mol. Biol. Evol. 4: 406-425.

Sakwinska O., Moine D., Delley M., Combremont S., Rezzonico E., Descombes P., Vinyes-Pares G., Zhang Y., Wang P., Thakkar
S.K. 2016. Microbiota in breast milk of Chinese lactating mothers. PloS One 11: e0160856.

Solis G., Reyes-Gavilan C.G., De Los Fernandez N., Margolles A., Gueimonde M. 2010. Establishment and development of lactic acid bacteria and bifidobacteria microbiota in breast milk and the infant gut. Anaerobe 16: 307-310.

Stecher G., Tamura K., Kumar S. 2020. Molecular evolutionary genetics analysis (MEGA) for macOS. Mol. Biol. Evol. 37: 1237-1239.

Suskovic J., Kos B., Beganovic J., Pavunc L.A., Habjanic K., Matosic S. 2010. Antimicrobial activity - the most important property of probiotic and starter lactic acid bacteria. Food Technol. Biotechnol. 48: 296-307.

Tamura K., Nei M., Kumar S. 2004. Prospects for inferring very large phylogenies by using the neighbor-joining method. Proc. Natl. Acad. Sci. USA 101: 11030-11035.

Tharmaraj N., Shah N.P. 2009. Antimicrobial effects of probiotics against selected pathogenic and spoilage bacteria in cheesebased dips. Int. Food Res. J. 16: 261-276.

van der Veer C., Hertzberger R.Y., Bruisten S.M., Tytgat H.L.P., Swanenburg J., Angelino-Bart A.K., Schuren F., Molenaar D., de Vries H., Kort R. 2019. Comparative genomics of human Lactobacillus crispatus isolates reveals genes for glycosylation and glycogen degradation: implications for in vivo dominance of the vaginal microbiota. Microbiome 7: 49.

van Hijum S.A.F.T., van Geel-Schutten G.H., Rahaoui H., van der Maarel M.J.E.C., Dijkhuizen L. 2002. Characterization of a novel fructosyltransferase from Lactobacillus reuteri that synthesizes high-molecular-weight inulin and inulin oligosaccharides. Appl. Environ. Microbiol. 68: 4390-4398.

Walker A. 2010. Breast milk as the gold standard for protective nutrients. J. Pediatr. 156: S3-S7.

Wright M.H., Adelskov J., Greene A.C. 2017. Bacterial DNA extraction using individual enzymes and phenol/chloroform separation. J. Microbiol. Biol. Educ. 18: 60.

Zhang X., Mushajiang S., Luo B., Tian F., Ni Y., Yan W. 2020. The composition and concordance of Lactobacillus populations of infant gut and the corresponding breast-milk and maternal gut. Front. Microbiol. 11: 597911.

Zivkovic A.M., German J.B., Lebrilla C.B., Mills D.A. 2011. Human milk glycobiome and its impact on the infant gastrointestinal microbiota. Proc. Natl. Acad. Sci. USA 108: 4653-4658. 